\title{
LEGISLAÇÃO EDUCACIONAL BRASILEIRA E A CONSTRUÇÃO DA AUTONOMIA NAS ESCOLAS
}

\author{
Eloênia Oliveira da Silva ${ }^{1}$ \\ Carlos Betlinski
}

\section{RESUMO}

Este artigo aborda o tema da autonomia da escola pública da Educação Básica considerando o viés do conhecimento da legislação educacional, um objeto de discussão que está longe de se esgotar. A preocupação central desta incursão teórica é com o conhecimento legal e com a formação política dos docentes e gestores escolares, uma vez que são entendidos como os principais sujeitos que atuarão como praticantes e promotores da autonomia escolar. Nesse contexto, elaboramos a seguinte indagação para orientar nossa investigação: qual o sentido do conhecimento da legislação educacional na formação docente, tendo em vista a construção da autonomia escolar? Como objetivos deste trabalho pretende-se apresentar algumas referências teóricas sobre o tema e argumentar sobre a importância dos atores escolares conhecerem e se exercitarem na prática da autonomia. Apoiamo-nos em referências teóricas de Carlos Jamil Cury, Licínio Lima, João Barroso, Vitor Henrique Paro e Moacir Gadotti para a análise do tema e, como resultados, argumentamos que, tanto na formação inicial, quanto na formação continuada de professores, torna-se imprescindível o conhecimento da legislação e a clareza das perspectivas políticas implícitas na legislação, uma vez que ela é suporte para o exercício da autonomia e construção da gestão democrática escolar.

Palavras-chaves: Legislação educacional brasileira. Gestão democrática. Autonomia.

\section{BRAZILIAN EDUCATIONAL LEGISLATION AND THE CONSTRUCTION OF AUTONOMY IN SCHOOLS}

\begin{abstract}
This article addresses autonomy in Brazilian Basic Education public school considering the bias of knowledge of educational legislation, a discussion object that is far from exhausting. Central concern of this theoretical study is related to legal knowledge and with teachers and school managers' political training, since they are seen as the main subjects who will act as practitioners and promoters of school autonomy. In this context, the following question was made to guide this research: What is the meaning of educational legislation knowledge in

\footnotetext{
1 Graduação em Direito. Mestranda do Programa de Pós-Graduação em Educação da Universidade Federal de Lavras - Email: eloenia.silva@estudante.ufla.br - Orcid: https://orcid.org/0000-0003-42590064

2 Professor de Filosofia de Educação do Programa de Pós-Graduação em Educação da Universidade Federal de Lavras. Email: carlosbetlinski@ufla.br - Orcid: https://orcid.org/0000-0003-1747-466X
} 
teacher training with a view to building school autonomy? This study aims to present some theoretical references on the subject and discuss the importance of school actors to know and to exercise themselves in the practice of autonomy. Theoretical references by Carlos Jamil Cury, Licínio Lima, João Barroso, Vitor Henrique Paro and Moacir Gadotti were used for the analysis of the topic. As results, it is argued that both in initial and in continuing teacher training legislation, knowledge and clarity of the political perspectives implicit in the legislation are essential, since it is support for the exercise of autonomy and construction of school democratic management.

Keywords: Brazilian educational legislation. Democratic management. Autonomy.

\section{Introdução}

As escolas têm por um de seus objetivos, a produção e mediação do conhecimento, sendo ainda palco para a reprodução de ideologias. Isto posto, as escolas entendidas aqui como unidades sociais, são integradas e estruturadas dentro de um sistema educativo de ensino composto por um contexto social, político, econômico e ideológico. (PREVIATTI e CASTANHO, 2007).

Dito isso, o presente trabalho de construção teórica parte incialmente da concepção conceitual dos termos "legislação educacional" e "autonomia". Nesse contexto teórico, foram abordados como fontes de embasamento argumentativo, os ensinamentos de Jamil Cury (2000), João Barroso (2004), Carmem Moreira de Castro Neves (1995), Licínio Lima (1988), dentre outros pesquisadores educacionais.

A seguir, é apresentada a relação existente entre a legislação educacional e a construção da autonomia relativa das escolas, sob o viés específico da previsão da autonomia das escolas a partir da legislação educacional brasileira. A análise da Constituição Federal de 1988 e a Lei de Diretrizes e Bases da Educação Nacional foram dois elementos-chave para a construção desse tópico teórico.

Ademais, dentro do tópico de investigação que norteou os escritos deste artigo é explicitado ainda, a diferença entre "autonomia decretada" e "autonomia construída", na concepção de João Barroso (1996), bem como, a realização do aprofundamento da perspectiva de que dentro das escolas existem 05 (cinco) autonomias relativas interdependentes, conforme ensinamentos de Moacir Gadotti (2003). Ainda nesse contexto teórico, aborda-se a necessidade de formação estruturada e qualificada dos atores sociais componentes do quadro da Educação, aqui entendidos como diretores, 
especialistas em educação básica e professores, em termos de legislação educacional brasileira, com a finalidade de desenvolvimento da autonomia individual desses atores educacionais.

Na sequência, é apresentada a construção da autonomia relativa das escolas como princípio de uma gestão democrática da educação. Nessa trajetória, infere-se que a alta responsabilidade em termos de políticas públicas colaborativas pode determinar as características de um sistema de ensino que, concretamente se paute na qualidade da educação como meio para a formação cultural democrática dos indivíduos.

A respeito da gestão democrática da educação, apresenta-se considerações sobre seus fundamentos teóricos com embasamento nas concepções de Vitor Henrique Paro (2017), Luiz Fernandes Dourado (2007), Cury (2007), entre outros autores. Buscou-se nesse momento, explicitar a influência que a construção de escolas autônomas e o desenvolvimento de gestões escolares participativas, possuem no alcance de um fim maior, no caso, na construção de uma gestão democrática da educação, como forma de promoção do exercício da cidadania.

Por fim, o presente artigo apresenta a relação entre legislação educacional brasileira e a construção da autonomia relativa das escolas, notadamente as de natureza pública, articulando, sob uma ótica sociológica, que as escolas não são unidades burocráticas do Estado, mas sim, um espaço democrático de exercício do poder compartilhado.

\section{Concepções conceituais dos termos: legislação educacional e autonomia das escolas}

Segundo o livro "Legislação Educacional Brasileira", de Carlos Roberto Jamil Cury, o primeiro ponto que se deve compreender a respeito de Legislação Educacional, é que os termos desse título são provenientes de uma origem etimológica. De acordo com esse autor, "o termo legislação é a junção de dois termos: legis + lação. Ambos provêm do latim. Legis é o genitivo de Lex e Latio (+ lação) provém de um verbo latino fero, ferre, tuli, latum." (CURY, 2000, p. 13). 
A partir destes dois termos, tem-se que a expressão lex/legis significa (lei/da lei), e, segundo alguns intérpretes, a expressão também pode ter a sua origem no verbo latino lego ou legere, que significa - ler a palavra que foi pronunciada e escrita - ou, transmitir a outrem a responsabilidade de fazer algo em virtude de um contrato. Já o termo lação (latio), significa levar, trazer, apresentar e transportar. (CURY, 2000).

Sob a perspectiva de Cury, não obstante o termo "legislação" possua significados variados, substancialmente a expressão representa:

[...] algo que foi "dito", que foi "escrito" sob a forma de lei e que está sendo apresentado ou que está se dando a conhecer ao povo, inclusive para ser lido e inscrito em nosso convívio social. A legislação, então, é uma forma de apropriar-se da realidade política por meio das regras declaradas, tornadas públicas, que regem a convivência social de modo a suscitar o sentimento e a ação da cidadania. Não se apropriar das leis é, de certo modo, uma renúncia à autonomia e a um dos atos constitutivos da cidadania. (CURY, 2000, p. 15).

Tendo como base o supramencionado na citação acima, é neste contexto de apropriação das leis, para o exercício do convívio social, que conhecer a legislação representa um ato de cidadania, que não deve ser restrito aos componentes do poder judiciário, legisladores, advogados e bacharéis em Direito. Afinal, é sob a perspectiva da democracia que a legislação ganha sentido, legitimidade e força de lei. (CURY, 2000).

Segundo o autor, de modo geral, entender a Legislação Educacional Brasileira, como um conjunto de leis que regulam matérias específicas afetas à seara da Educação, é o mesmo que dizer que "a lei é tanto um momento de formalização de práticas sociais como orientação para as políticas públicas da educação nacional". (CURY, 2000, p.79).

Cumpre salientar que, dentro da seara da Educação existem diversos órgãos executivos e normativos, por exemplo, em nível federal existe o MEC (Ministério da Educação), cuja função é elaborar e executar políticas educacionais, e, o Conselho Nacional de Educação, que se manifesta por meio da expedição de Resoluções procedentes de Pareceres homologados pela autoridade executiva competente e possui funções normativas, consultivas/deliberativas (interpretação da legislação 


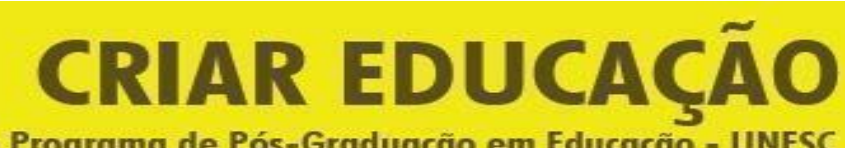

Revista do Programa de Pós-Graduação em Educação - UNESC

Criar Educação, Criciúma, v. 9, № 3, ago/dez. 2020 - PPGE - UNESC - ISSN 2317-2452

educacional para a sua devida aplicação) e de assessoramento ao Ministro de Estado da Educação, no desempenho das funções e atribuições do poder público federal em matéria de educação.

Por sua vez, em nível estadual e municipal, existem os Conselhos Estaduais e Municipais de Educação, que possuem funções normativas, consultivas/deliberativas e de assessoramento as Secretarias Estaduais e Municipais de Educação, os quais possuem função executiva, normativa e consultivas/deliberativas e de assessoramento ao Governador do Estado e Prefeitos dos Municípios, respectivamente. (CURY, 2000).

Isto posto, percebe-se que no contexto legal cada órgão acima mencionado, tem autonomia para expedir comandos normativos de acordo com suas atribuições específicas no âmbito da Educação, que devem ser, por via de consequência, seguidos por toda comunidade educacional. Por conseguinte, é necessário que os atores sociais, aqui destacados como diretores, especialistas em educação básica e professores que compõem os quadros das escolas, notadamente as de natureza pública, consigam visualizar que tais comandos normativos possuem hierarquia entre si.

Além disso, é preciso reconhecer que regularmente no cotidiano escolar será indispensável que a comunidade educacional saiba distinguir, mediante 0 conhecimento da legislação educacional brasileira, qual imperativo deve ser hierarquicamente seguido, uma vez que nas palavras do pesquisador educacional João Barroso: "Os decretos, portarias e outros normativos sucedem-se numa lógica aditiva que faz com que coexistam, sincrónica ou diacronicamente, medidas similares, contraditórias ou recorrentes num processo sedimentar de difícil elucidação". (BARROSO, 2004, p. 50).

Lado outro, em relação à perspectiva conceitual da expressão "autonomia das escolas", tem-se que a origem etimológica do termo "autonomia" provém da junção de dois termos gregos: autos + nomos, que significam, respectivamente, (si mesmo/lei). Assim, autonomia representa o sentido de autoconstrução, autogoverno, autogestão. (PREVIATTI e CASTANHO, 2007). 


\title{
CRIAR EDUCAÇÃO
}

Revista do Programa de Pós-Graduação em Educação - UNESC

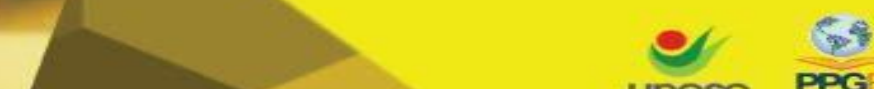

unesc PPG:

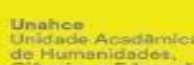

Criar Educação, Criciúma, v. 9, nº 3, ago/dez. 2020 - PPGE - UNESC - ISSN 2317-2452

As pesquisadoras da Educação, Areta Held Previatti e Maria Eugênia Castanho (2007), no artigo "A autonomia das escolas públicas: limites e possibilidades" defendem que apenas existe autonomia escolar quando:

a unidade é capaz de se autogovernar, tomar decisões, ter representação, fixar normas, poder optar e decidir questões internas. A autonomia é uma questão pedagógico-administrativa, mas acima disso é uma questão política e histórica. Sendo assim, "não existe uma autonomia absoluta, ela será sempre relativa e determinada historicamente". (GADOTTI, 2003, p. 10). (PREVIATTI e CASTANHO, 2007, p. 400).

Sob a perspectiva da citação supramencionada, as autoras entendem que sem o governo de si mesmas (autonomia relativa), as escolas, notadamente as de nível público, são sinteticamente terminais cumpridores de normas e circulares do Ministério da Educação. E como tais, o seu objetivo é reduzido às questões de tarefas burocráticas, dados e resultados quantitativos. (PREVIATTI e CASTANHO, 2007).

Ainda, neste mesmo cenário teórico, atinente à autonomia relativa das escolas, o intelectual brasileiro, João Barroso (1996) no livro "O estudo da autonomia da escola: da autonomia decretada à autonomia construída", pontua que:

\begin{abstract}
A autonomia é um conceito relacional (somos sempre autónomos de alguém ou de alguma coisa) pelo que a sua acção se exerce sempre num contexto de interdependência e num sistema de relações. A autonomia é também um conceito que exprime um certo grau de relatividade: somos mais, ou menos, autónomos; podemos ser autónomos em relação a umas coisas e não o ser em relação a outras. A autonomia é, por isso, uma maneira de gerir, orientar, as diversas dependências em que os indivíduos e os grupos se encontram no seu meio biológico ou social, de acordo com as suas próprias leis. (BARROSO, 1996, p. 17).
\end{abstract}

Como se vê, de acordo com a ótica de João Barroso, as instituições educativas possuem autonomia relativa, uma vez que para o exercício de suas atividades devem se submeter às legislações de cunho geral e de cunho específico, tais como: a Constituição Federal de 1988, Lei de Diretrizes e Bases da Educação Nacional, Diretrizes Curriculares, normas expedidas pelas Secretarias de Educação e Conselho Nacional de Educação, dentre outras. Dessa forma, não obstante as escolas possuam autonomia decretada com previsão em dispositivos legais, como forma de promoção do princípio da gestão democrática, percebe-se de modo epistemológico, que essa 
autonomia ainda necessita ser construída, tanto do ponto de vista das escolas como dos sistemas de ensino.

Ademais, esse mesmo pesquisador educacional, adaptando o conceito de "igualdade de oportunidades" de François Dubet, que entende que "a igualdade de oportunidades é, portanto, uma fiç̧ão necessária. Uma ficção porque é pouco provável que ela se realize totalmente; necessária porque não é possível educar sem se acreditar nela" (DUBET, 2004, p. 38), para o conceito de "autonomia das escolas", compreende que raramente essa dita autonomia não tem sido uma ficção.

Segundo o autor, em contextos fáticos e sob uma perspectiva crítica, poucas são as vezes em que a autonomia das escolas ultrapassa o discurso político e se aproxima de sua concretização efetiva, contudo, tal autonomia tornou-se uma "ficção legal necessária", destinada ao contexto de estratégia política, para legitimar os objetivos de controle e administração por parte do governo. (BARROSO, 2004).

Nesse viés da autonomia relativa das escolas, é importante trazer à baila 0 entendimento de Carmem Moreira de Castro Neves (1995), no livro "Autonomia da escola pública: um enfoque operacional", que defende a autonomia relativa das escolas como:

[...] um exercício de democratização de um espaço público: é delegar ao diretor e aos demais agentes pedagógicos a possibilidade de dar respostas ao cidadão (aluno e responsável) a quem servem, em vez de encaminhá-lo para órgãos centrais distantes onde ele não é conhecido e, muitas vezes, sequer atendido. A autonomia coloca na escola a responsabilidade de prestar contas do que faz ou deixa de fazer, sem repassar para outro setor essa tarefa e, ao aproximar escola e famílias, é capaz de permitir uma participação realmente efetiva da comunidade, o que caracteriza como uma categoria eminentemente democrática (NEVES, 1995, p. 99).

Com foco no entendimento supra aludido, é possível compreender que uma efetiva autonomia relativa das escolas, possibilitaria o desenvolvimento dos seus aspectos pedagógicos, administrativos e financeiros, além de viabilizar a participação cotidiana dos diversos atores sociais que contribuem para o processo de tomada de decisões das escolas. Porém, essa autonomia relativa necessita ser compreendida como um processo de construção e não como um processo meramente burocrático, com enfoque operacional político. 
A seu turno, não admira que, Licínio Lima (1998), em seu estudo a respeito da evolução da administração educativa, à época da Reforma Educativa (1987-1991), tenha asseverado que:

Do ponto de vista da lógica reformista, iniciada em 1986, parecerá difícil não concluir que a "reforma da administração do sistema educativo e das escolas" terá sido uma reforma fracassada. Com efeito, a análise aqui conduzida revela como o paradigma da administração centralizada tem persistido, como do ponto de vista normativo o "modelo" de 1976 continuou, de facto, e generalizadamente, a vigorar, como as promessas e as expectativas em torno da autonomia das escolas permaneceram por cumprir. (LIMA, 1998, p. 80).

Assim sendo, é possível hipoteticamente sustentar que, o estado de letargia nacional que assolava as escolas naquele tempo da "Reforma Educativa", subsiste ainda nos tempos atuais, se analisarmos que em contextos fáticos a administração das escolas ainda permanece sendo exercida de forma centralizada. Porém, agora com contornos diferentes, dada a dinamicidade das relações sociais, políticas e econômicas que permeiam o sistema educacional.

Insta ressaltar que, a construção da autonomia relativa das escolas, é uma forma de reforçar as identidades destas e reconhecer que dentro de certos limites e condições, os órgãos representativos das escolas são capazes de exercer uma gestão escolar de melhor qualidade quando comparada ao gerenciamento da administração central ou regional. Sendo certo, que essa autonomia não deve ser compreendida como uma forma do Estado aligeirar as suas responsabilidades, mas sim, uma forma interdepende de promoção de uma gestão escolar democrática de qualidade (BARROSO, 2004), que deve ser compreendia a partir do seu fundamento legal dado pelas previsões normativas contidas na legislação educacional brasileira, sendo esse último melhor delineado na subseção seguinte.

\section{A autonomia das escolas a partir da legislação educacional brasileira}

Partindo do pressuposto de que, sem a autonomia relativa das escolas não é possível o desenvolvimento qualitativo de uma gestão escolar democrática, a Constituição Federal de 1988 e a Lei de Diretrizes e Bases da Educação expressaram normativamente em seus textos a tutela ao direito à autonomia, liberdade e gestão 
democrática das escolas, notadamente as escolas de ensino público. (PREVIATTI e CASTANHO, 2007).

De acordo com o artigo $1^{\circ}$ e 0 artigo 206, ambos da Constituição Federal de 1988, constitui-se como princípio fundamental do Estado Democrático de Direito, a participação democrática da população, sendo dever do Estado e de todos, a proteção ao pluralismo de ideias e concepções pedagógicas e a gestão democrática do ensino, notadamente do ensino público. Por sua vez, a Lei de Diretrizes e Bases da Educação, em seus artigos 14 e 15, regulamenta, respectivamente, que: "Art. 14 - Os sistemas de ensino definirão as normas da gestão democrática de ensino público básico" e que “Art. 15 - Os sistemas de ensino assegurarão às unidades escolares públicas de educação básica que os integram progressivos graus de autonomia pedagógica, administrativa e de gestão financeira". (PREVIATTI e CASTANHO, 2007).

Todavia, é importante salientar que é difícil vislumbrar a construção da autonomia relativa das escolas que, por via de consequência, propiciaria 0 desenvolvimento qualitativo de uma gestão escolar democrática, quando as normas, orientações curriculares e pacotes pedagógicos são elaborados e definidos exclusivamente por órgãos exteriores às unidades escolares. Passados, quase 24 (vinte e quatro) anos da promulgação da Lei de Diretrizes e Bases da Educação, a tão sonhada autonomia das escolas é ainda praticamente imperceptível dentro do sistema educacional brasileiro. (PREVIATTI e CASTANHO, 2007).

Para além dessa perspectiva crítica, a respeito da autonomia relativa das escolas brasileiras, o pesquisador educacional, Moacir Gadotti (2003, p. 10), cita que a autonomia relativa das escolas pode ser dividida em 05 (cinco) espécies interdependentes:

- Autonomia filosófica - valores que são transformados em fins e objetivos.

- Autonomia política - frente à política educacional.

- Autonomia administrativa - operacionalizar os objetivos políticos e filosóficos.

- Autonomia pedagógica - capacidade de definir o currículo da escola.

- Autonomia didática - liberdade em relação às atividades de ensinoaprendizagem.

Nesse contexto teórico, é possível perceber que a verdadeira construção da autonomia relativa das escolas vai além da descentralização do seu setor 
administrativo e pedagógico. Isso porque, as escolas são agora compreendidas como construções sociais, cujo papel dos indivíduos e o contexto social e histórico da sua ação, representam função elementar nesse processo de "construção da autonomia"3. Segundo Barroso, tal processo de construção corresponde ao "jogo de dependências e de interdependências que os membros de uma organização estabelecem entre si e com o meio envolvente e que permitem estruturar a sua acção organizada em função de objectivos colectivos próprios." (BARROSO, 1996, p. 10).

A este propósito, a pesquisadora Berta Macedo assinala que:

A escola aumenta a sua autonomia através das múltiplas dependênciasinteracções que estabelece com os outros sistemas, tendo em conta as necessidades e finalidades que identifica. É na multiplicidade de dependências, de inter-relações, que se criam condições favoráveis à integração da escola no processo de desenvolvimento da sociedade. A variedade das dependências que desenvolve produz diferença. A gestão destas dependências é autonomia de escola. (MACEDO, 1995, p. 87).

Assim, a concepção teórica dessa pesquisadora corrobora com o entendimento exposto anteriormente por Barroso, no viés de que a autonomia relativa das escolas é o resultado da confluência de vários interesses e do equilíbrio de forças entre diferentes detentores de influência interna e externa (governo e seus representantes), presentes no campo político, pedagógico e gestionário. Sendo a interação dos diferentes atores de influência interna, aqui destacados como diretores, especialistas em educação básica, docentes, alunos, pais e membros da comunidade local, que por sua vez, possuem suas autonomias individuais, a expressão de uma unidade social representada pela existência das escolas.

Motivo pelo qual, Barroso (1996) sustenta que, para que a autonomia individual desses atores sociais, notadamente de diretores, especialistas em educação básica e docentes, seja colocada ao serviço de determinados objetivos organizacionais das

\footnotetext{
${ }^{3} \mathrm{~A}$ adoção de uma perspectiva crítica no estudo da autonomia da escola obriga, por isso, a distinguir as várias lógicas presentes no processo de devolução de competências aos órgãos de governo da escola, separando dois níveis de análise: a autonomia decretada e a autonomia construída.

No primeiro caso, trata-se de desconstruir os discursos legitimadores das políticas de descentralização e de autonomia das escolas, interpretando as formas e fundamentos das medidas que são propostas e, ao mesmo tempo, confrontando-as com as estruturas existentes e as contradições da sua aplicação prática.

No segundo caso, trata-se de reconstituir os "discursos" das práticas, através de um processo de reconhecimento das formas de autonomia emergentes no funcionamento das escolas, nas estratégias e na acção concreta dos seus actores. (BARROSO, 1996, p. 01).
} 


\title{
CRIAR EDUCAÇÃO
}

Revista do Programa de Pós-Graduação em Educação - UNESC

Criar Educação, Criciúma, v. 9, № 3, ago/dez. 2020 - PPGE - UNESC - ISSN 2317-2452

escolas, com a finalidade de desenvolver um processo coletivo de mudança que priorize a construção da autonomia relativa das escolas, se faz necessário o desenvolvimentos de 03 (três) tipos de intervenção:

\begin{abstract}
- Promover na escola "uma cultura de colaboração e de participação entre todos os que asseguram o seu funcionamento, incluindo a própria definição e a realização dos objectivos organizacionais.

- Desenvolver nas escolas formas diversificadas (individuais e colectivas) de liderança, sem a qual não se podem empreender os difíceis e complexos processos de coesão necessários a que a escola se constitua como um sujeito social coerente e encontre o justo equilíbrio entre as diversas referências que podem inspirar a acção educativa (para citar Derouet, 1992, para quem o funcionamento da escola é, essencialmente uma questão de "justeza" e de "justiça"). -

- Aumentar o conhecimento, por parte dos próprios membros da organização, dos seus modos de funcionamento e das regras e estruturas que a governam. Esta aprendizagem organizacional (da e pela organização) constitui um instrumento necessário para que os actores de uma organização conheçam o seu próprio campo de autonomia e o modo como está estruturado. (BARROSO, 1996, p. 11).
\end{abstract}

Segundo Barroso (1996), uma escola que conhece a sua comunidade educacional, o modo como ela está estruturada e busca o desenvolvimento da autonomia individual de seus próprios membros, de modo que eles tenham uma consciência crítico-reflexiva de suas ações praticadas no cotidiano escolar e responsabilidade social que advém da refletividade de tais ações, é uma escola que prima pela autonomia como um pressuposto para a construção de um processo de mobilização social. Por isso, entender a construção da autonomia relativa das escolas, como uma forma de reforçar o princípio da gestão escolar democrática, é também uma forma de construir uma cultura democrática.

Partindo de todos os pressupostos até então delineados e tendo neste momento como foco à autonomia individual de gestores escolares e docentes, uma indagação se faz pertinente e necessária: De que forma o conhecimento da legislação educacional brasileira pode incentivar e qualificar esses atores sociais que compõem as escolas brasileiras, no desenvolvimento de sua autonomia individual?

Com a finalidade de responder a essa indagação reflexiva, primeiramente trazemos à baila as palavras do autor Maurice Tardif, em sua obra denominada "Saberes Docentes e Formação Profissional", sob a perspectiva de que "o ensino exige do trabalhador a capacidade de utilizar, na ação cotidiana, um vasto leque de 


\section{CRIAR EDUCAĈ̃AO}

Revista do Programa de Pós-Graduação em Educação - UNESC
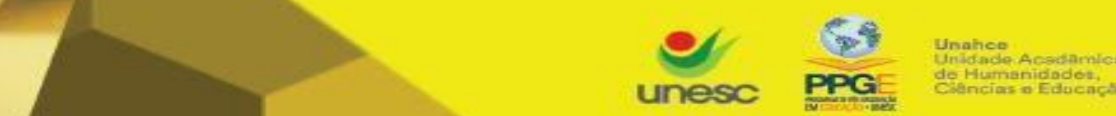

unese

Criar Educação, Criciúma, v. 9, ㄲo 3, ago/dez. 2020 - PPGE - UNESC - ISSN 2317-2452

saberes compósitos". (TARDIF, 2002, p. 66). Dentro do campo de experiência e atuação de gestores escolares e docentes, Tardif assinala que esses "saberes":

[..] quando vistos como saberes-na-ação (knowing-in-action) (Schon, 1983), parecem ser fundamentalmente caracterizados pelo "polimorfismo do raciocínio" (George, 1997), isto é, pelo uso de raciocínios, de conhecimentos, de regras, de normas e de procedimentos variados, decorrentes dos tipos de ação nas quais o autor está concretamente envolvido com os outros. [...] (TARDIF, 2002, p. 66, grifos nossos).

Portanto, um dos conhecimentos (saberes) que estão presentes na atuação docente e na gestão escolar, são os conhecimentos de regras e normas, notadamente do ordenamento normativo referente ao campo educacional (legislação educacional). Nas palavras de Cury, o ideal a ser perseguido pelos profissionais da educação deve ser o domínio do "(...) ordenamento normativo de seu campo profissional, de seu campo de interesse e de sua sociedade." (CURY, 2002, p. 9), posto que não é razoável que gestores escolares e docentes ignorem a Lei de Diretrizes e Bases da Educação, Estatuto do Magistério, Acordos Sindicais, dentre outros, na medida em que na qualidade de profissionais do ensino, a expectativa é que eles devem conhecêlas mais do que os outros cidadãos comuns. (CURY, 2002).

Deste modo, tanto quanto um direito, a formação inicial e continuada de profissionais da Educação, oportunamente nesse momento, com foco na formação pertinente ao conhecimento da legislação educacional brasileira, é definida em nosso ordenamento jurídico como um dever do Estado. Motivo pelo qual, a Lei no 9.394/96 comumente conhecida por Lei de Diretrizes e Bases da Educação Nacional, preceitua em seu artigo 62, $\S 1^{\circ}$, que "A União, o Distrito Federal, os Estados e os Municípios, em regime de colaboração, deverão promover a formação inicial, a continuada e a capacitação dos profissionais de magistério".

Assim sendo, em reposta a indagação anteriormente aqui formulada, infere-se que a inserção de profissionais educacionais em cursos de formação inicial e continuada que, contemplem a necessidade de formação aprofundada no conhecimento da legislação do seu campo profissional (legislação educacional) e da sociedade em que vive, possui influência direta na prática das ações desses profissionais. Sendo certo, que essa formação estruturada e qualificada representa as condições necessárias para a construção do exercício da autonomia individual, que 
Secretarias de Educação e instituições, como uma forma efetiva de controle às unidades escolares.

Segundo as pesquisadoras da Educação, Areta Held Previatti e Maria Eugênia Castanho, o supramencionado decreto potencializava a hierarquização entre os órgãos educacionais, sendo eles: "Gabinete do secretário, Coordenadoria de Normas, Coordenadoria de Ensino, Divisão Regional e Especial de Ensino, Delegacia de Ensino e por último a unidade escolar." (PREVIATTI e CASTANHO, 2007, p. 396). Mas, em 1995 a Divisão Regional e Especial de Ensino, foram extintas pelo Decreto de no 39.902 e suas funções deslocadas para os outros órgãos educacionais que ainda permaneceram ativos.

$\mathrm{Na}$ concepção das pesquisadoras acima aludidas, na estrutura de uma escola burocrática existe uma dicotomia entre dirigentes e executores, cujo poder de tomada de decisão e o controle, estão depositados nas mãos dos órgãos educacionais superiores restando apenas às escolas, a função de executar as tarefas que lhe são impostas e prestar contas aos órgãos superiores. (PREVIATTI e CASTANHO, 2007). Dessa forma, "[...] a escola burocrática não forma governantes, mas governados." (GADOTTI, 2003, p. 55).

Paro (2002) assinala que, a exacerbada racionalização de normas, regulamentos e documentos, com a finalidade de regular as atividades e os procedimentos do cotidiano escolar, muitas das vezes comprometem o processo educativo, por estarem desvinculados da realidade e se mostrarem inadequados para as soluções dos problemas que ocorrem no interior das escolas. Portanto, é possível inferir que, "a luta pela autonomia da escola é principalmente contra a burocracia." (PREVIATTI e CASTANHO, 2007, p. 398).

É em consonância com essa perspectiva e no intuito de melhorar a qualidade da educação brasileira, que Gadotti afirma:

A luta pela autonomia da escola insere-se numa luta maior pela autonomia no seio da própria sociedade. Portanto, é uma luta dentro do instituído, contra o instituído, para instituir outra coisa. A eficácia dessa luta depende muito da ousadia de cada escola em experimentar o novo caminho de construção da confiança na escola e na capacidade dela resolver seus problemas por ela mesma, confiança na capacidade de autogoverna-se (GADOTTI, 1995, p. 202). 
Logo, pensar na autonomia da sociedade, sobretudo nas políticas públicas educacionais e na gestão democrática da educação no território brasileiro, a partir da defesa de um processo educativo de qualidade, é pensar nas convergências e divergências dos modos de regulação dos sistemas de ensino, previstos legalmente nos ordenamentos jurídicos brasileiros. Nesse cenário, em um discurso voltado à descentralização do ensino, Luiz Fernandes Dourado em seu artigo "Políticas e gestão da educação básica no brasil: limites e perspectivas", afirma que:

\begin{abstract}
Assegurar condições políticas e de gestão para o envolvimento e a participação da sociedade civil na formulação, implementação das ações e programas de universalização da educação básica, bem como a melhoria da educação nos diferentes níveis e modalidades, é tarefa dos poderes públicos. No Brasil, dada a natureza patrimonial do Estado, muito há que ser feito, a fim de garantir a participação da sociedade civil nas políticas públicas, especialmente na educação. (DOURADO, 2007, p. 939).
\end{abstract}

Para efeito dessa afirmativa e considerando a especificidade do sistema educacional brasileiro, é que o artigo 205 da Constituição Federal de 1988 deixa claro que "a educação, direito de todos e dever do Estado e da família, será promovida e incentivada com a colaboração da sociedade, visando ao pleno desenvolvimento da pessoa, seu preparo para o exercício da cidadania e sua qualificação para o trabalho.". Dessa definição bela e forte, é estreme de dúvidas que, pensar nas escolas como instituições que têm o condão de contribuir para a transformação social significa "tomar consciência das condições concretas, ou das contradições concretas, que apontam para a viabilidade de um projeto de democratização das relações no interior da escola." (PARO, 2017, p. 13).

Diante de todo o exposto, é possível perceber que à nível ideológico existem possivelmente 02 (duas) lógicas antagônicas no cenário da educação brasileira. Uma que defende um sistema educacional centralizador, burocrático e hierarquizado e outra que defende um sistema descentralizado, participativo, autônomo relativamente e integrado. E, por mais tautológico que pareça ser, a racionalização centralizadora e burocrática provavelmente está mais presente do que se imagina, na teoria e na prática da gestão das escolas brasileiras.

Por isso, o debate a respeito da construção da autonomia relativa das escolas como princípio de uma gestão democrática da educação, nunca se fez tão substancial, 
na medida em que em termos de conjuntura fática, a racionalidade técnica neoliberal ${ }^{4}$ existente no discurso que fundamenta as políticas públicas educacionais, reforça uma postura tecnicista dentro do sistema educacional brasileiro. E, esse discurso visivelmente representa um contrassenso ao processo de desenvolvimento da formação cultural e construção de uma sociedade democrática pautada pelo sentido humanista da educação escolar e pela racionalidade estética.

De acordo com o perseverante pensamento de Vitor Henrique Paro (2017), em "Gestão Democrática da Escola Pública", é necessário se aproveitar das contradições existentes na realidade social como molas propulsoras destinadas à transformação social e não utilizar o discurso da supremacia dos determinantes estruturais como explicação para a letargia nacional, aguardando-se que milagrosamente a sociedade se transforme em uma nação verdadeiramente democrática, e, por via de consequência, as escolas se transformem em instituições sociais embasadas em uma gestão escolar democrática. Afinal, "a democracia não se concede, se realiza." (PARO, 2017, p. 26).

Nas palavras literais de Cury, gestão democrática da educação é:

ao mesmo tempo, por injunção da nossa Constituição (art. 37) (BRASIL, 1988): transparência e impessoalidade, autonomia e participação, liderança e trabalho coletivo, representatividade e competência. Voltada para um processo de decisão baseado na participação e na deliberação pública, a gestão democrática expressa um anseio de crescimentos dos indivíduos como cidadãos e do crescimento da sociedade enquanto sociedade democrática. Por isso a gestão democrática é a gestão de uma administração concreta. (CURY, 2007, p. 494).

E nesse contexto teórico de gestão democrática da educação, antes de tudo, é importante ressaltar que no entendimento do pesquisador supramencionado, essa

\footnotetext{
${ }^{4}[\ldots]$ capaz de orientar internamente a prática efetiva dos governos, das empresas e, para além deles, de milhões de pessoas que não têm necessariamente consciência disso. O neoliberalismo define certa norma de vida [...] que impõe a cada um de nós que vivamos num universo de competição generalizada, intima os assalariados e as populações a entrar em luta econômica uns contra os outros, ordena as relações sociais segundo o modelo do mercado, [...] obriga a justificar desigualdades cada vez mais profundas, muda até o indivíduo, que é instado a conceber a si mesmo e a comportar-se como uma empresa. Trata-se de uma nova razão do mundo, cujo sucesso normativo pode ser descrito como político, econômico, social e subjetivo, enfim, integra todas as dimensões da existência humana. [...] 0 neoliberalismo antes de ser uma ideologia ou uma política econômica, é em primeiro lugar e fundamentalmente uma racionalidade e, como tal, tende a estruturar e organizar não apenas a ação dos governantes, mas até a própria conduta dos governados. (DARDOT e LAVAL, 2016, p.15-16)
} 
gestão inicialmente representa tanto uma abertura ao diálogo quanto à busca permanente de caminhos reflexivos e concretos que conduza à democratização das escolas brasileiras. Sendo certo que, o escopo final é o de materializar o direito à educação mediante um processo significativo de ensino-aprendizagem.

Afirma-se rotineiramente em discursos ideológicos que, a escola além de ser um espaço de desenvolvimento do processo de ensino-aprendizagem é também um lócus de construção da democracia. Daí a importância de se pensar o processo de construção da gestão democrática da educação, que representa uma macroesfera, iniciando-se pela construção da autonomia relativa das escolas, que tem por objetivo propiciar o desenvolvimento gradativo de uma gestão escolar democrática, que neste caso representa uma microesfera.

Dessa forma, pensar na construção da autonomia relativa das escolas como princípio de uma gestão democrática da educação, é indubitavelmente pensar em uma sociedade mais justa, humana e igualitária, onde todos tenham a oportunidade de "desenvolver-se como seres humanos fortes intelectualmente, ajustados emocionalmente, capazes tecnicamente e ricos de caráter." (FERREIRA, 1998, p. 113).

\section{Considerações finais}

Refletir sobre a construção da autonomia relativa das escolas, a partir do conhecimento da legislação educacional brasileira, significa opor-se ao pensamento tecnicista de que normas e leis são ferramentas burocráticas que somente privilegiam um sistema educacional centralizado e hierarquizado. Isto porque, conhecimento representa poder aos indivíduos, não sendo plausível imaginar, que transformações sociais à nível interno de escolas e à nível externo de sistema educacional e sociedade, possam ser possíveis de se concretizar sem a apreensão do conhecimento necessário do aparato legal que regula a possibilidade dessas transformações sociais.

Por isso, o conhecimento, enquanto emancipação, no presente contexto teórico assenta-se na possibilidade dos atores sociais inseridos no campo educacional reivindicarem e participarem da elaboração de políticas públicas educacionais que 


\section{CRIAR EDUCAÇÃO \\ Revista do Programa de Pós-Graduação em Educação - UNESC}

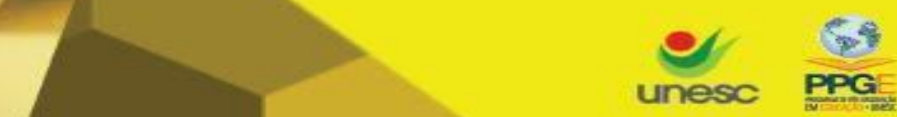

Criar Educação, Criciúma, v. 9, ㄲo 3, ago/dez. 2020 - PPGE - UNESC - ISSN 2317-2452

sejam mais condizentes com a realidade e problemas vivenciados pelas escolas brasileiras, em atenção ao princípio da gestão democrática da educação. Assim, como ao mesmo tempo, propicia às escolas a construção de sua autonomia relativa como forma de promoção de uma gestão escolar democrática, sob essa perspectiva, "a autonomia impõe um novo padrão de política, planejamento e gestão educacionais, tanto do ponto de vista da escola como dos sistemas de ensino." (NEVES,1995, p. 97).

Nesse contexto de construção da autonomia relativa das escolas, gestão democrática e de melhor incentivo e qualificação à comunidade educacional em relação ao conhecimento da legislação educacional brasileira, com o escopo de ter uma educação de qualidade, e, por via de consequência, uma sociedade mais justa, igualitária e democrática, muito se tem ainda que realizar para que esses valores se tornem uma realidade. Pois, como ensina Dourado, Oliveira e Santos (2007), a qualidade da educação envolve múltiplas dimensões indispensáveis ao desenvolvimento do processo ensino-aprendizagem, de modo que compreendia como um fenômeno complexo "a qualidade da educação é definida envolvendo a relação entre os recursos materiais e humanos, bem como a partir da relação que ocorre na escola e na sala de aula [...]." (DOURADO, OLIVEIRA e SANTOS, 2007, p. 9).

Tendo por pressuposto a concepção de que uma educação de qualidade é um fenômeno complexo e abrangente, o presente artigo buscou compreender a articulação existente entre o conhecimento da legislação educacional brasileira e a construção da autonomia relativa das escolas. A partir desse referencial teórico, foi possível a promoção de um debate dialético entre as possibilidades e limites de uma gestão escolar autônoma e democrática, e, a compreensão de que a própria escola é capaz de encontrar soluções para os seus problemas sociais internos.

Do mesmo modo que é possível inferir que, os limites para a construção e exercício dessa autonomia relativa que aponta para uma gestão escolar democrática, são parte integrante de um contexto teórico que perpassa necessariamente pelo estudo e formação do conhecimento a partir da legislação educacional brasileira. Portanto, para a construção de uma gestão escolar democrática que permita modificar suas concepções práticas em benefício da comunidade escolar, a compreensão 
CURY, Carlos Roberto Jamil. A gestão democrática na escola e o direito à educação. RBPAE - v.23, n.3, p. 483-495, set./dez. 2007. Disponível em: https://seer.ufrgs.br/rbpae/article/view/19144/11145

. Legislação educacional brasileira. Rio de Janeiro: DP\&A, 2000.

DARDOT, P.; LAVAL, C.. A nova razão do mundo: ensaio sobre a sociedade neoliberal. São Paulo: Editora Boitempo, 2016.

DOURADO, Luiz Fernandes. Políticas e gestão da educação básica no Brasil: limites e perspectivas. Educ. Soc., Campinas, vol. 28, n. 100 - Especial, p. 921946, out. 2007. Disponível em: http://www.scielo.br/pdf/es/v28n100/a1428100.pdf

DOURADO, L.F.; OLIVEIRA, J.F.; SANTOS, C.A. A qualidade da educação: conceitos e definições. Brasília, DF: INEP, 2007.

DUBET, François. L'école des Chances. Qu'est-ce qu'une école juste? Paris: Éditions du Seuil et La Republique des Idées, 2004.

FERREIRA, N. S. C. A gestão da Educação e as políticas de formação de profissionais da educação: desafios e compromissos. In: FERREIRA, N. S. C. (Org.). Gestão democrática da Educação: atuais tendências, novos desafios. São Paulo: Cortez, 1998.

GADOTTI, Moacir. A autonomia como estratégia da qualidade de ensino e a nova organização do trabalho na escola. Petrópolis: Vozes, 1995.

Nossa Época, v. 24).

Escola cidadã. 9.ed. São Paulo: Cortez, 2003. (Coleção Questões da

Lei no 9.394/96. Lei de Diretrizes e Bases da Educação Nacional. Disponível em: http://www.planalto.gov.br/ccivil_03/leis/19394.htm

LIMA, Licínio C. A administração do sistema educativo e das escolas (1986/1996). In: AAVV, A Evolução do Sistema Educativo e o PRODEP. Estudos Temáticos, vol I. Lisboa: DAPP. Ministério da Educação, 1998, pp. 15-95.

Organização Escolar e Democracia Radical: Paulo Freire e a Governação Democrática da Escola Pública. São Paulo: Cortez Editora, 2000.

MACEDO. Berta. A construção do Projecto Educativo de Escola. Lisboa: Instituto de Inovação Educacional, 1995.

NEVES, Carmem Moreira de Castro. Autonomia da escola pública: um enfoque operacional. In: VEIGA, IIma Passos A (Org.). Projeto Político-Pedagógico da escola: uma construção possível. Campinas, SP: Papirus, 1995.

PARO, V. H. Administração escolar: introdução e crítica. São Paulo:

Cortez/Autores Associados, 1998.

2017.

Gestão democrática da escola pública. 4.ed. São Paulo: Cortez Editora,

PREVIATTI, Areta Held. CASTANHO, Maria Eugênia. A autonomia da escola

pública: limites e possibilidades. Educação Temática Digital, Campinas, v.8, n. 3, 


\section{CRIAR EDUCAÇÃO}

Revista do Programa de Pós-Graduação em Educação - UNESC

Criar Educação, Criciúma, v. 9, № 3, ago/dez. 2020 - PPGE - UNESC - ISSN 2317-2452

p.393-409, dez. 2007. Disponível em:

https://periodicos.sbu.unicamp.br/ojs/index.php/etd/article/view/754

SILVA, J. M. A autonomia da escola pública: a re-humanização da escola. 4.ed. Campinas, SP: Papirus, 1996. (Coleção Práxis).

TARDIF, Maurice. Saberes docentes e formação profissional. Petrópolis, RJ: Vozes, 2002.

Recebido em junho de 2020 Aprovado em setembro de 2020 